\title{
Frequency response analysis under faults in weak power systems
}

\author{
Marino Godoy Arcia ${ }^{1}$, Zaid García Sánchez ${ }^{1}$, Hernán Hernández Herrera ${ }^{2}$, José Antonio González- \\ Cueto Cruz ${ }^{1}$, Jorge Iván Silva-Ortega ${ }^{3}$, Gustavo Crespo Sánchez ${ }^{1}$ \\ ${ }^{1}$ Center of Energy and Environmental Studies-Department, Universidad de Cienfuegos, Cienfuegos, Cuba \\ ${ }^{2}$ Facultad de Ingenierías, Universidad Simón Bolívar, Barranquilla, Colombia \\ ${ }^{3}$ Departamento de Energía, Universidad de la Costa, Barranquilla, Colombia
}

\begin{tabular}{l} 
Article Info \\
\hline Article history: \\
Received Dec 23, 2020 \\
Revised Oct 27, 2021 \\
Accepted Nov 10, 2021 \\
\hline
\end{tabular}

Keywords:

Frequency fluctuations

Frequency response

Isolate power systems

Renewable energy sources

penetration

Weak distribution networks

\begin{abstract}
The renewable energy sources (RESs) projects are solutions with environmental benefits that are changing the traditional power system operation and concept. Transient stability analysis has opened new research trends to guarantee a secure operation high penetration. Problems such as frequency fluctuations, decoupling between generator angular speed, network frequency fluctuation and kinetic energy storing absence are the main non-conventional RESs penetration in power systems. This paper analyzes short-circuit influence on frequency response, focusing on weak distribution networks and isolated, to demonstrate relevance in frequency stability. A study case considered a generation outage and a load input to analyze frequency response. The paper compares frequency response during a generation outage with a short-circuit occurrence. In addition, modular value and angle generator terminal voltage affectation by electric arc and network ratio RX, failure type influence in power delivered behavior, considering fault location, arc resistance and load. The arc resistance is defined as an added resistance that appears during failure and influences voltage modulus and angle value results showing that intermittent nonconventional RES participation can lead to frequency fluctuations. Results showed that arc resistance, type of failure, location and loadability determine the influence of frequency response factors in weak power systems.
\end{abstract}

This is an open access article under the CC BY-SA license.

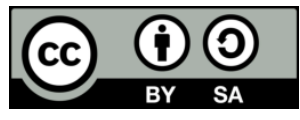

\section{Corresponding Author:}

Hernán Hernández Herrera

Facultad de Ingeniería, Universidad Simón Bolívar

Barranquilla, Colombia

Email: hernan.hernandez@unisimonbolivar.edu.co, hernanhh813@gmail.com

\section{INTRODUCTION}

Since the last decade, renewable energy sources (RESs) penetration is changing the electric power systems (EPSs) energy matrix. Agents used to reduce conventional unit participation in daily load graph coverage [1]-[4]. RESs bring multiple benefits for EPSs and environment, but some of them, such as photovoltaic and wind power generators, have intermittent electrical energy production, which can produce frequency fluctuations [5]-[11].

Another disadvantage is that RESs connection to the EPSs is through converters, this produces decoupling between generator angular speed and network frequency, as occurs in several wind turbine applications [12]-[18]. Also, solar photovoltaic generation is static and do not store kinetic energy. These two technologies do not contribute to primary frequency control [19], [20]. Static converters photovoltaic, wind generation and batteries energy storage systems affect the total EPSs inertia ratio, so this effect on 
frequency deviations has become a topic of interest when an EPSs consider the participation of these electrical energy sources with high penetration [21]. Frequency stability emerges as the major problem in modern EPSs operation. The frequency variation in the EPSs voltage is one of the most important operation variables. Its magnitude deviation, regarding its nominal value, can have detrimental effects for both consumers and EPSs elements that make them up. Frequency deviations are inversely proportional to rotating total inertia of the machine and system disturbance caused by them. This disturbance can be a load variation, generating unit disconnection, transformer or transmission line opening, or a short circuit event.

In this context, isolated EPSs show a more pronounced event behavior of this phenomenon since they are weak systems that do not have interconnection with other areas allowing frequency behavior improvement against disturbances [22]-[24]. Also, they have a lower inertia and supported by RESs. Many researches in this field aim to address this problem and its solution. Unlike isolated systems, large EPSs has a large-scale generation units' arrangement, they are robust interconnected transmission networks and operate with spinning reserve values which guarantee that frequency stability is not a dangerous phenomenon. In these EPSs, the attention to voltage collapse and its related problems is a priority [25]-[27], transient angle instability problems and a recent priority search for characterize small disturbance angle instability problems.

CIGRE/IEEE defines different EPSs stability categories [28]. This definition shows each category and analyzes the procedures considered on its evaluation. RESs in isolated EPSs evaluating methodologies are detailed in [29]. Especially in frequency stability studies, emphasis is placed on failures to be analyzed as well as on generation units' behavior and EPSs in general [30]. In study [29], it is described the behavior of a generator during faults. They speed up, followed by a sudden load reduction in voltage collapse caused by faults; the rotor angle also experiences an increase when the machine acceleration occurs. This behavior is in correspondence with a frequency increase. While a short circuit effect on a high nominal voltage power system occurs, control agents used to notice a frequency increase most time caused by the failure event, then a voltage drop is reported and there is a resulting link between machines, showing a high $\mathrm{X} / \mathrm{R}$ ratio.

However, generalizing this is incorrect, because of there is a dependence on this behavior with machines' load initial state and X/R relationships that may remain in network equivalent positive sequence links. Isolated local networks have specific characteristics and favorable conditions can be present in order to failures cause a frequency reduction that leads low-frequency and/or frequency variation protection operation. Real cases in which ground faults have caused a frequency decrease and low frequency disconnections have presented. This has been this research motivation which aims to analyze short-circuit influence on frequency behavior in isolated electrical networks and to show this phenomenon analysis relevance in frequency stability. A sudden frequency reduction in short circuit events and low frequency protections operation make necessary to include failure simulation in frequency stability studies. These aspects impact the generation penetration effects with static converters.

\section{RESEARCH METHOD}

\subsection{Frequency stability in electric power systems (EPSs)}

Modern literature defines the frequency stability in an EPSs, as the ability to maintain an adequate frequency value in a steady state caused by sudden generation-load imbalance occurrences [28]. Instability events include sustained frequency oscillation that can cause generators and/or loads to trip. Four welldefined stages appear in frequency behavior caused by a generation and load imbalance. Figure 1 show these stages. The first stage is the inertial response of the units, in which the kinetic energy stored in the rotating units assumes part of power imbalance and therefore contains frequency deviation. Second stage is the primary frequency control, in which the speed drive of the synchronous units begins with the aim of frequency restoring and stabilize into a value close to nominal. The frequency steady state error is the difference between nominal frequency value and the value at which frequency reaches its stable levels, this is called frequency steady state error. The minimum frequency value in EPS response is conditioned by these two previous stages. This point is relevant to EPS frequency stability.

Subsequently, a secondary control action occurs, which allows frequency recuperation to its nominal value minutes after disturbance occurrence. The fourth stage is the tertiary control, which depends on EPSs generation matrix, as it depends on the possibility to have a quick-start unit that allows the restoration of the network secondary control reserves. A unit generation loss or a sudden load increase cause frequency behavior described in Figure 1. During short-circuits generators usually speed up, causing an increase in frequency equations that describe synchronous generator behavior.

\subsection{Synchronous generator behavior}

Two opposite torques causes the synchronous generator rotation. The mechanical contribution caused by turbine $T_{m}$ and the electromagnetic torque $T_{e}$. Mechanical torque speed up the rotor, while 
electromagnetic torque slows it down. In normal operation these two torques are equal, therefore there is no acceleration torque $T_{a}$ and the synchronous generator rotates at synchronous speed. Equation (1) describes this behavior:

$$
J \frac{d^{2} \theta_{r}}{d t^{2}}=T_{a}=\left(T_{m}-T_{e}\right)
$$

being $J$ the inertia moment and $\theta_{r}$ the rotor angle.

Typically, this rotor motion is expressed in power terms instead of torque, and as an angle $\delta$ function that rotates at synchronous speed, therefore as shown in (1) can be written:

$$
\frac{2 H}{w_{s}} \frac{d^{2} \delta}{d t^{2}}=P_{a}=P_{m}-P_{e}
$$

where: $w_{S}$ : synchronous speed

$H$ : Inertia constant

$P_{a}$ : Acceleration power

$P_{m}$ : Mechanical power supplied by primary source.

$P_{e}$ : Electrical output power

Equation (2) defines the synchronous machine oscillation equation. An important term in EPSs stability, $H$ constant or inertia constant which defines the machine capacity or kinetic energy and as shown in (3) defines it as follows:

$$
H=\frac{E_{\text {kinetic }}}{S_{\text {machine }}}=\frac{1}{2} \frac{J w_{s}^{2}}{S_{\text {machine }}}
$$

where $S_{\text {machine }}$ represents MVA machine capacity. This constant appears within machines defined data to carry out stability studies. The stored kinetic energy provides inertial response and primary frequency control.

To determine the electrical behavior of the synchronous generator (4)-(9) calculate the machine fem variation in direct axes and in excitation field quadrature, all expressed in per unit on nominal data of machine capacity, frequency, and voltage.

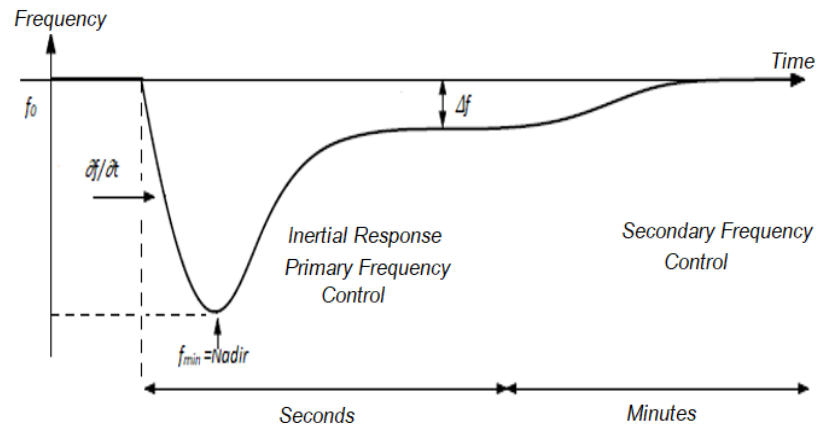

Figure 1. Frequency behavior stages in generation loss event

$$
\begin{aligned}
& E_{q}^{\prime \prime}-V_{q}=R_{a} i_{q}+X_{d}^{\prime \prime} i_{d} \\
& E_{d}^{\prime \prime}-V_{d}=R_{a} i_{d}-X_{q}^{\prime \prime} i_{q} \\
& \frac{d E_{q}^{\prime}}{d t}=\frac{1}{T_{d 0}^{\prime}}\left[E_{f}-\left(E_{q}^{\prime}-\left(X_{d}^{\prime}-X_{d}\right) i_{d}\right)\right] \\
& \left.\frac{d E_{d}^{\prime}}{d t}=-\frac{1}{T_{q 0}^{\prime}}\left[E_{d}^{\prime}-\left(X_{q}^{\prime}-X_{q}\right) i_{q}\right)\right]
\end{aligned}
$$




$$
\begin{aligned}
& \frac{d E_{q}^{\prime \prime}}{d t}=\frac{1}{T_{d 0}^{\prime \prime}}\left[E_{q}^{\prime}-\left(X_{d}^{\prime}-X_{d}^{\prime \prime}\right) i_{d}-E_{q}^{\prime \prime}\right] \\
& \frac{d E_{d}^{\prime \prime}}{d t}=\frac{1}{T_{q 0}^{\prime \prime}}\left[E_{d}^{\prime}-\left(X_{q}^{\prime}-X_{q}^{\prime \prime}\right) i_{q}-E_{d}^{\prime \prime}\right]
\end{aligned}
$$

In these equations $E_{d}^{\prime \prime}, E_{d}^{\prime}, E_{q}^{\prime \prime}$ and $E_{q}^{\prime}$ are sub-transient and transient fem corresponding to direct axes and machine field quadrature; $V_{d}, V_{q}, i_{d}$, and $i_{q}$ terminal voltage and armature current components in both axes; $E_{f}$ armature fem proportional to machine applied excitation voltage, $T_{d 0}^{\prime \prime}, T_{d 0}^{\prime}, T_{q 0}^{\prime \prime}$ and $T_{q 0}^{\prime}$ both axes sub-transient and transient time constants corresponding to buffering and field windings; $X_{d}^{\prime \prime}, X_{d}^{\prime}, X_{q}^{\prime \prime}$ and $X_{q}^{\prime}$ quadrature and direct axis sub transient and transient reactance and $R_{a}$ machine armature resistance. That variables and sub-transient constants establish a relation with buffering and field transient winding flux concatenations. In these equations when applied to protruding pole machines, if there is no buffering winding in interpolate area or its effect is neglected, a necessary adjustment must be made in corresponding direct axis equations since $E_{d}^{\prime}$ does not exist under these conditions. The (10) and (11) calculate active and reactive power delivered by machine at its terminals, respectively.

$$
\begin{aligned}
& P_{\text {delivered }}=V_{q} i_{q}+V_{d} i_{d} \\
& Q_{\text {delivered }}=V_{q} i_{d}-V_{d} i_{q}
\end{aligned}
$$

Magnitudes transformation on $d, q$ axes to corresponding magnitudes on real and imaginary axes can be calculated using (12) and (13) relation:

$$
\begin{aligned}
& {\left[\begin{array}{l}
V_{r} \\
V_{i}
\end{array}\right]=\left[\begin{array}{cc}
\cos (\delta) & \sin (\delta) \\
\sin (\delta) & -\cos (\delta)
\end{array}\right]\left[\begin{array}{l}
V_{q} \\
V_{d}
\end{array}\right]} \\
& {\left[\begin{array}{l}
V_{q} \\
V_{d}
\end{array}\right]=\left[\begin{array}{cc}
\cos (\delta) & \sin (\delta) \\
\sin (\delta) & -\cos (\delta)
\end{array}\right]\left[\begin{array}{l}
V_{r} \\
V_{i}
\end{array}\right]}
\end{aligned}
$$

where $\delta$ is rotor angle, as expressed in (2), measured with respect to a real axis that rotates at synchronous speed and that serves as a reference to all system phasors in which machine is connected. This angle is calculated for each machine using (14).

$$
\left|E_{Q}\right| e^{i \delta}=V_{r m}+\left(R_{a}+i X_{q}\right) I_{r m}
$$

Equation set from (1) to (9) allows to obtain machine rotor speed and position while known its terminal voltage, which must be calculated from system electrical network solution by using load flow equations. For this, nonlinear differential and algebraic equations solving numerical methods can be used, which allow calculating and performing system voltage and frequency behavior in disturbances presence (15) is obtained from (4) and (5) which means currents can be calculated as follows:

$$
\left[\begin{array}{l}
i_{q} \\
i_{d}
\end{array}\right]=\frac{1}{R_{a}^{2}+X_{q}^{\prime \prime} X_{d}^{\prime \prime}}\left[\begin{array}{cc}
R_{a} & -X_{d}^{\prime \prime} \\
X_{q}^{\prime \prime} & R_{a}
\end{array}\right]\left[\begin{array}{l}
E_{q}^{\prime \prime}-V_{q} \\
E_{d}^{\prime \prime}-V_{d}
\end{array}\right]
$$

Substituting in (10), power delivered is expressed in (16) as a sub-transient fem and terminal voltage function:

$$
\begin{aligned}
& P_{\text {delivered }}=\left(\frac{1}{R_{a}^{2}+X_{d}^{\prime \prime} X_{q}^{\prime \prime}}\right)\left[Z_{q}^{\prime \prime} E_{q}^{\prime \prime} V_{r m} \cos \left(\delta-\theta_{V}-\theta_{q}^{\prime \prime}\right)\right. \\
& +Z_{d}^{\prime \prime} E_{d}^{\prime \prime} V_{r m} \sin \left(\delta-\theta_{V}-\theta_{d}^{\prime \prime}\right)-R_{a} V_{r m}^{2}+\frac{1}{2}\left(X_{d}^{\prime \prime}\right. \\
& \left.\left.-X_{q}^{\prime \prime}\right) V_{r m}^{2} \sin \left(2\left(\delta-\theta_{V}\right)\right)\right]
\end{aligned}
$$

This (16), as a variable and sub-transient constant's function, can be expressed in the same way with transient and steady state variables. In this case are required to adjust according to machine field type and consider that 
in stable state fem direct axis is zero. Comparison between one machine power delivered and those obtained by a general numerical method in presence of system disturbance is permitted by this equation. In asymmetric fault case, the following correction must be made by using (17).

$$
P_{\text {activedelivered }}=P_{\text {delivered }}-\left[R_{2} I_{2}^{2}+\left(R_{0}+3 R_{N}\right) I_{0}^{2}\right]
$$

Power $\left(P_{e}\right)$ to be used in (2) will be given by $P_{\text {delivered }}$ or $P_{\text {active delivered }}$ according to each case, plus armature copper losses, given by $R_{a}\left(i_{q}^{2}+i_{d}^{2}\right)=R_{a} I_{1}^{2}$. Where $I_{1}, I_{2}$ and $I_{0}$ are machine phase currents symmetrical components.

All the (1)-(17) can be used in iterative calculation processes if saturation effect is considered. The (16) is exact for initial pre-fault and fault conditions at the time instant in which failure occurs. This equation graph as $\delta$ function could also be obtained by an iterative process to readjust saturation values.

\subsection{Isolated electrical power systems frequency behavior}

Isolated electrical systems have characteristics that make frequency stability an important aspect. These electrical systems power plants are usually supported by diesel internal combustion engines. These units have the particularity of low $H$ constant. That connected diesel units cover high demand value is another aspect that characterizes isolated EPSs and therefore when a generation trip occurs, an appreciable load fraction of total generation is lost. Consequently, isolated electrical power systems when face generation loss or sudden load connection, frequency fall rate is high and often low-frequency protections operation and/or $d f / d t$ is necessary to avoid EPS collapse. This is accentuated with RESs insertion with technologies decoupled from network through converters, which makes EPS further reduce energy stored in synchronous units.

\section{RESULTS AND DISCUSSION}

\subsection{Study case electrical power system description}

The selected study case is an isolated EPS which has an internal combustion units' generation composition, with low inertia values. During daylight the attendant units are photovoltaic power plants, located in two busbar sand a wind farm in five. There are seven loads located, as is shown in Figure 2.

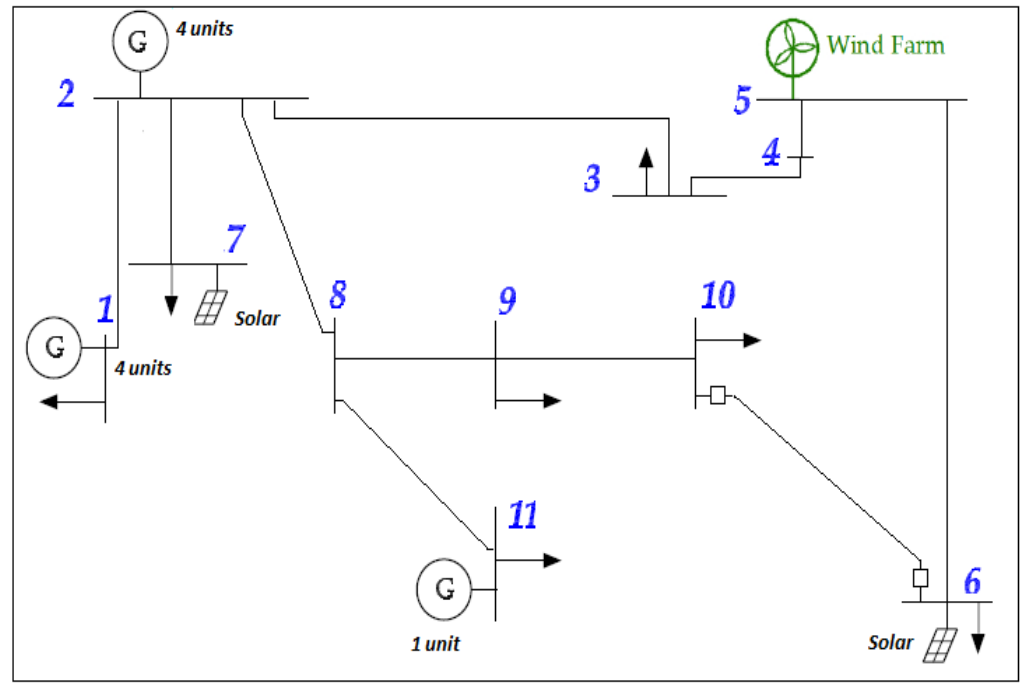

Figure 2. Electrical power system studied

Residential load predominates in the system, with $17 \mathrm{MW}$ of maximum demand approximately during the first night hours. Figure 3(a) shows electricity demand behavior when the maximum demand reached in 2019. Figure 3(b) shows the typical behavior for a solar and wind generation summer day. Figures 3(a) and 3(b) analysis exhibit the moments where demand peak is highest, which corresponds to solar photovoltaic generation reduction with and wind generation poor contribution. This is an interest moment for frequency regulation. 


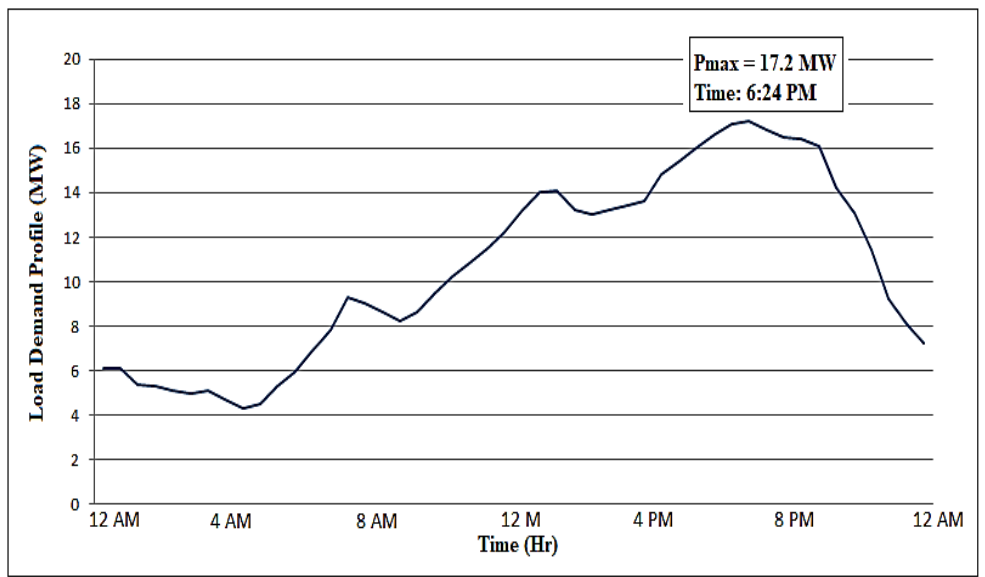

(a)

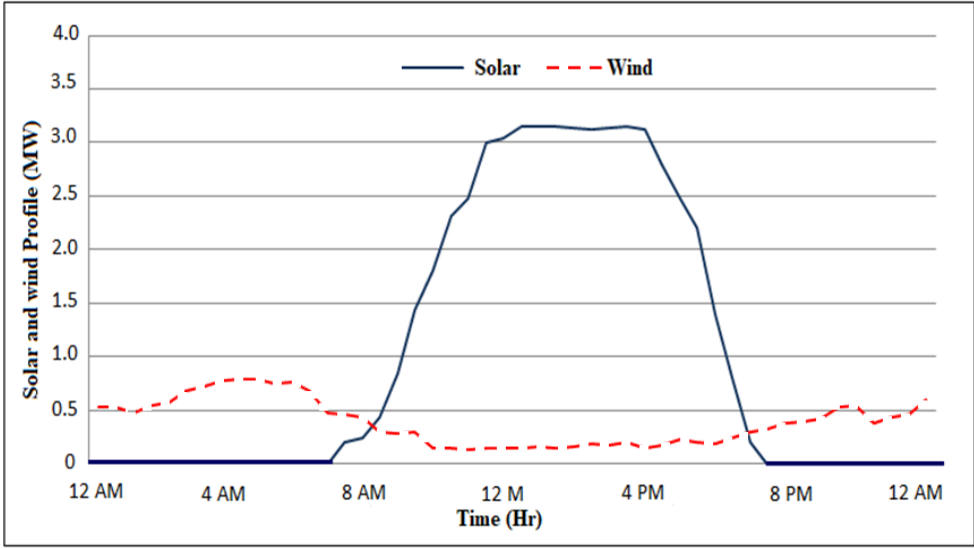

(b)

Figure 3. Demand and RESs generation profile where (a) demand daily behavior and (b) typical solar and wind generation in electrical system study case

\subsection{Real event modeling}

One of the most important aspects in electrical power systems studies is to establish an adequate correspondence between simulations and actual EPSs behavior. Results precision, conclusion, recommendations, and measures proposed pertinence in carrying studies out to guarantee previous aspect. Following modeling correspond to biphasic ground fault occurrence in an electrical system line of the study case. Unsuccessfully protections reclosing occurs as failure is permanent. Second protection operation performs permanent opening in the failed line.

Network operation state corresponds to $12.5 \mathrm{MW}$ of demand. Table 1 shows voltage, active and reactive power demand on each load $V_{0}, P_{0}$ and $Q_{0}$, respectively. In generation, nodes case voltage and active and reactive power generation $V_{0}, P_{G}$ and $Q_{G}$ are shown.

Table 1. Electric power system initial operating conditions

\begin{tabular}{cccccc}
\hline Bus & $\mathrm{V}_{0}(\mathrm{pu})$ & $\mathrm{P}_{0}(\mathrm{MW})$ & $\mathrm{Q}_{0}(\mathrm{Mvar})$ & $\mathrm{P}_{\mathrm{G}}(\mathrm{MW})$ & $\mathrm{Q}_{\mathrm{G}}(\mathrm{Mvar})$ \\
\hline 1(Two Units) & 1.04 & 5.4 & 2.04 & 6.26 & 4.32 \\
2(Two Units) & 1.00 & 0.0 & 0.0 & 6.26 & 2.34 \\
3 & 0.98 & 1.49 & 0.78 & 0.0 & 0.0 \\
4 & 0.98 & 0.0 & 0.0 & 0.0 & 0.0 \\
5 & 0.97 & 0.0 & 0.0 & 0.0 & 0.0 \\
6 & 0.97 & 1.02 & 0.70 & 0.05 & 0.0 \\
7 & 0.98 & 2.37 & 1.23 & 0.0 & 0.0 \\
8 & 0.96 & 0.57 & 0.19 & 0.0 & 0.0 \\
9 & 0.96 & 1.25 & 0.70 & 0.0 & 0.0 \\
10 & 0.96 & 0.40 & 0.40 & 0.0 & 0.0 \\
\hline
\end{tabular}


Figure 4 describes the frequency behavior after disturbance occurred. The behavior is in correspondence to frequency meter description that recorded the event. Note that in moments after failure, frequency drops until protections operate first time, frequency recovers. First reclosing moment occurs, and failure event remains, a sudden frequency decrease occurs, causing low-frequency protections operation. Subsequently, definitive protections operation occurs.

This event was modelled using data obtained from utilities generators, speed governors and voltage regulators modeling were carried out in correspondence with manufacturer data offered. Figure 5 shows frequency behavior, the minimum frequency value obtained as well as disconnected load because of low frequency are in correspondence with what happened in the actual event. The Accuracy level reached help to establish an adequate correspondence between modeling and actual system.

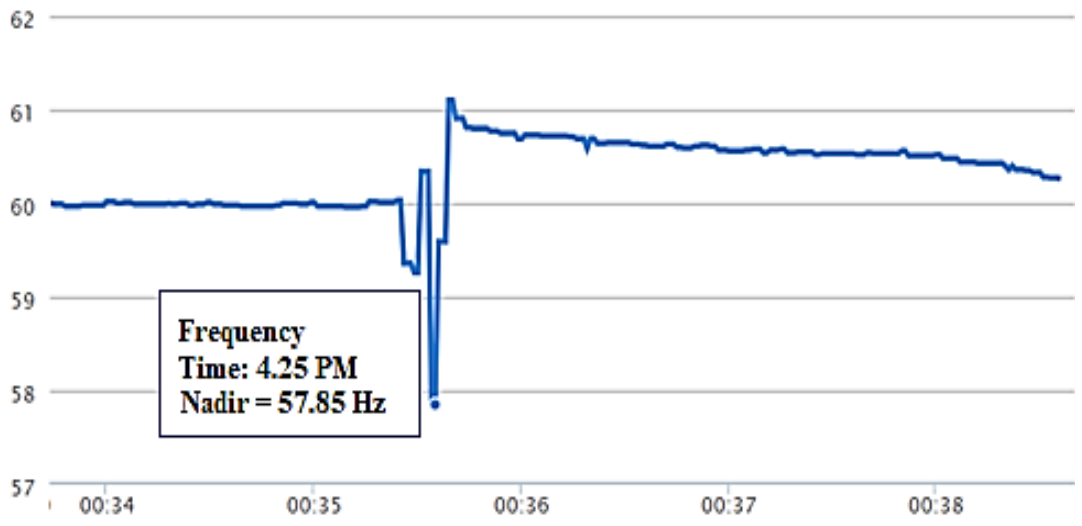

Figure 4. Actual frequency measured by frequency counter during failure studied

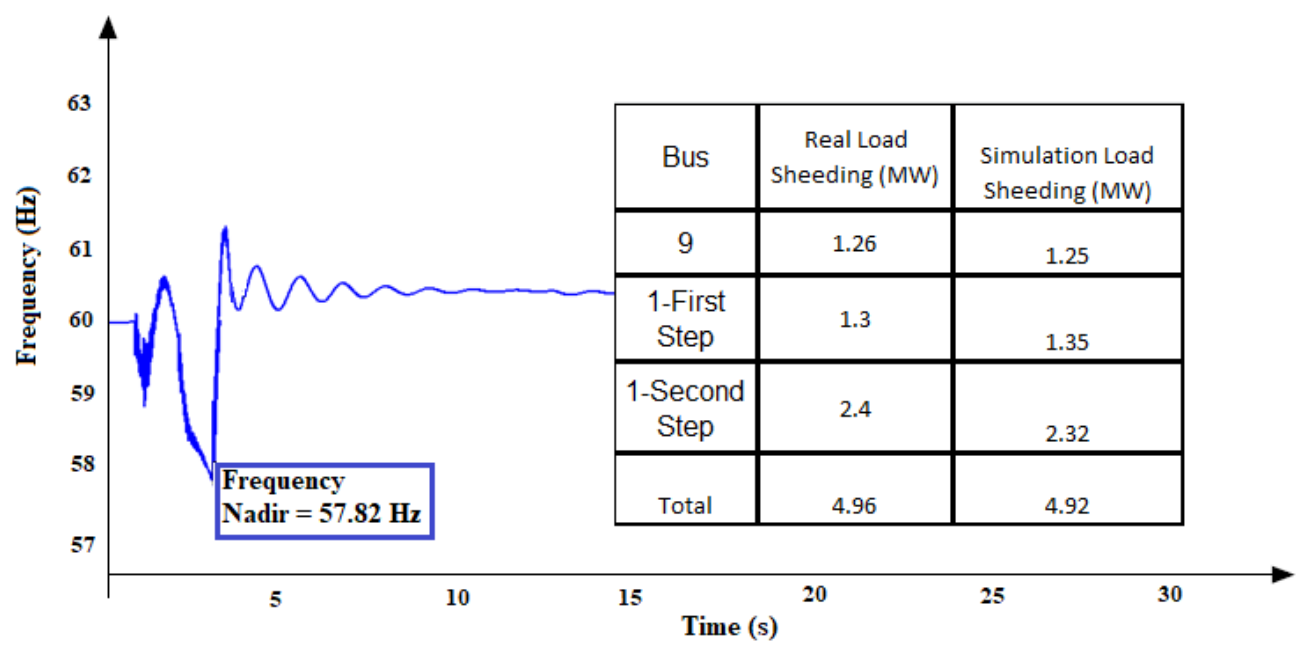

Figure 5. Frequency vs time in failure simulation

\subsection{Generation loss vs short circuit}

Frequency stability studies usually test frequency behavior in generation loss event or sudden load input. As shown in actual fault analyzed, short circuits effect in this network type can cause frequency instability problems. A comparison between EPSs frequency behavior generation loss event and short circuit occurrence is shown in Figure 6. During simulations system demand was $15 \mathrm{MW}$ and a $3 \mathrm{MW}$ of generation was disconnected, which represents $20 \%$ of total system demand, and the short circuit analyzed was a singlephase to ground at node 3 with a $19 \Omega$ arc resistance.

Figure 6 describes the frequency behavior when these two faults occur. Note that in short circuit occurrence case, minimum frequency value (nadir) is less by almost $4 \mathrm{~Hz}$ than the case of $20 \%$ generation loss. In both cases, low frequency protections operate, removing 5.8 MW of load from service. 


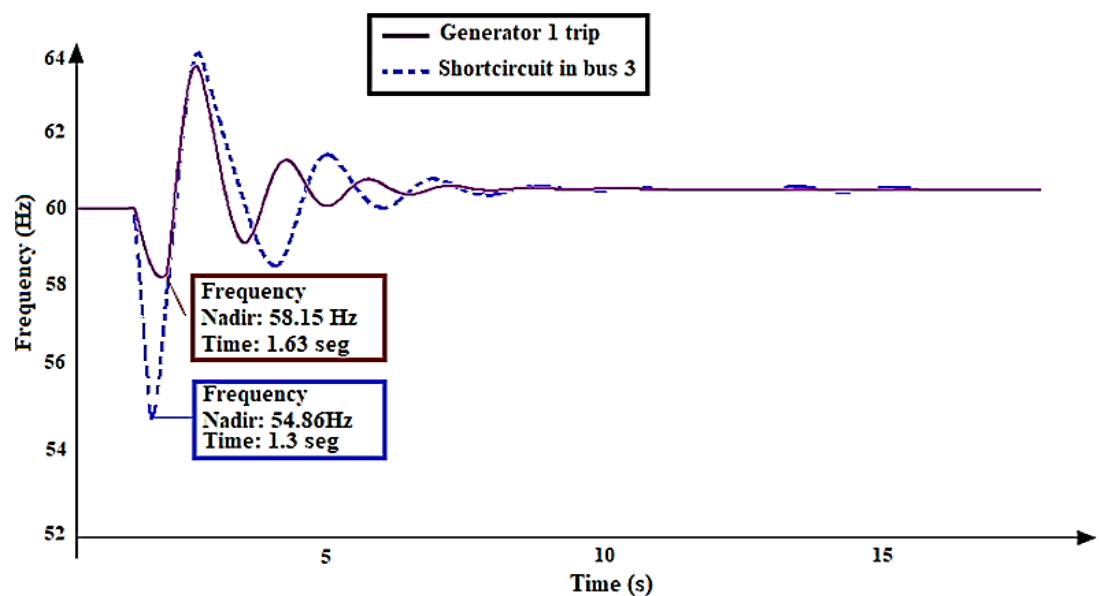

Figure 6. Frequency behavior in short circuit and generation loss events

\subsection{Generation behavior affecting factors}

That independent variables of generator constructive characteristics influence its behavior in short circuits events is allowed by (6). Generation power supply is influenced by the network place where failure occurs. The presence of electric arc and network ratio R/X are factors that affect modular value and angle generator terminal voltage. It also influences electrical power and internal generator fem in pre-fault conditions. Failure type is another factor that influences in generator power delivered behavior, as can be seen in (17).

\subsection{Fault location}

The failure location influences network frequency behavior. A comparison between frequency behavior when a single-phase short circuit to ground occurs at node 2 and at node 9 is shown in Figure 7(a). In both cases, when short-circuit occurs, frequency falls unlike what is traditionally expressed stability books of electric power system. In large electrical power systems, power supply by generators decreases however, in both cases there is an increase in electrical power delivered by generator 1 during failure as is showed in Figure 7(b). Frequency falls when a failure occurs at fault at node 2 and 9 but there are substantial differences in the minimum frequency value, and in frequency value rate change.

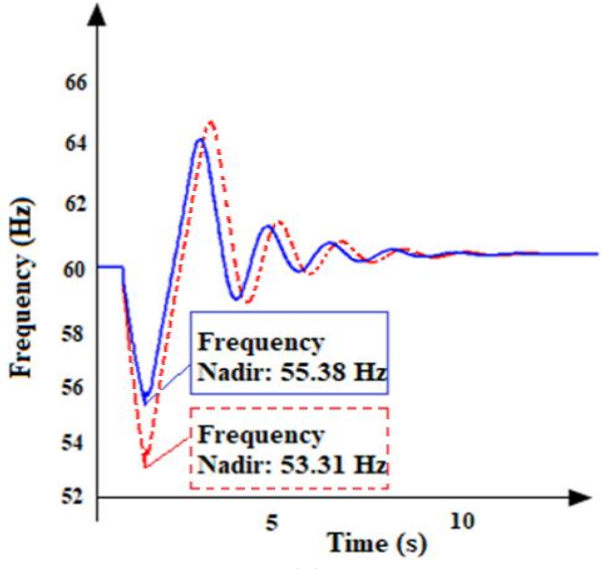

(a)

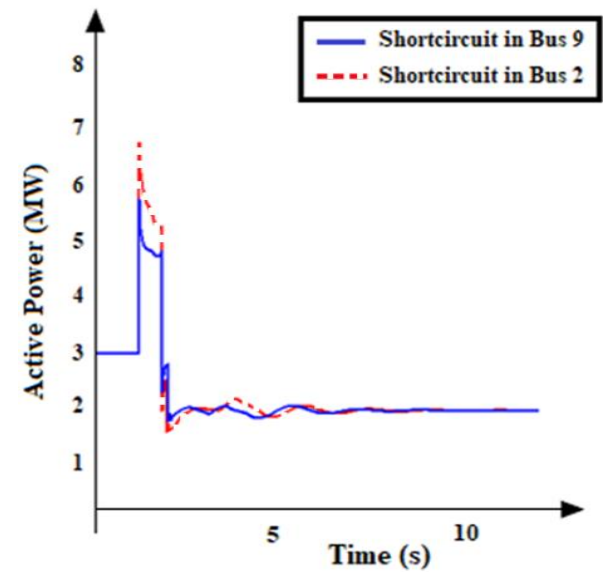

(b)

Figure 7. Short-circuit analysis (a) frequency behavior over time and (b) electric power delivered

\subsection{Failure type}

The failure is another aspect that influences generator behavior. Figures 8 shows the frequency fluctuations for different short circuits type at node. That failure occurs with a $19 \Omega$ resistance electric arc, 
and $150 \mathrm{~ms}$ failure duration is considered for several cases. There are differences in frequency behavior prior to different types of short circuits occurrence for single phase to ground and biphasic to ground frequency drops. In a single-phase short circuit to ground case, a low-frequency protections operation occurs $420 \mathrm{~ms}$ after the occurrence of the failure, removing 5.8 MW from service. In biphasic short circuit to ground case, a minimum frequency value does not reach low frequency protections settings and therefore, in failure event, there is no effect in users.

Separate mention deserves three-phase short circuit to ground. Initially, frequency increases until protections act and clear the fault. At this moment there is a sudden frequency decrease to values below low frequency protections adjustment, causing a disconnection of 5.8 MW, 1.56 seconds after fault occurrence. Either in single-phase short-circuit to ground case or in three-phase to ground case that frequency instability phenomenon occurs Figure 8.

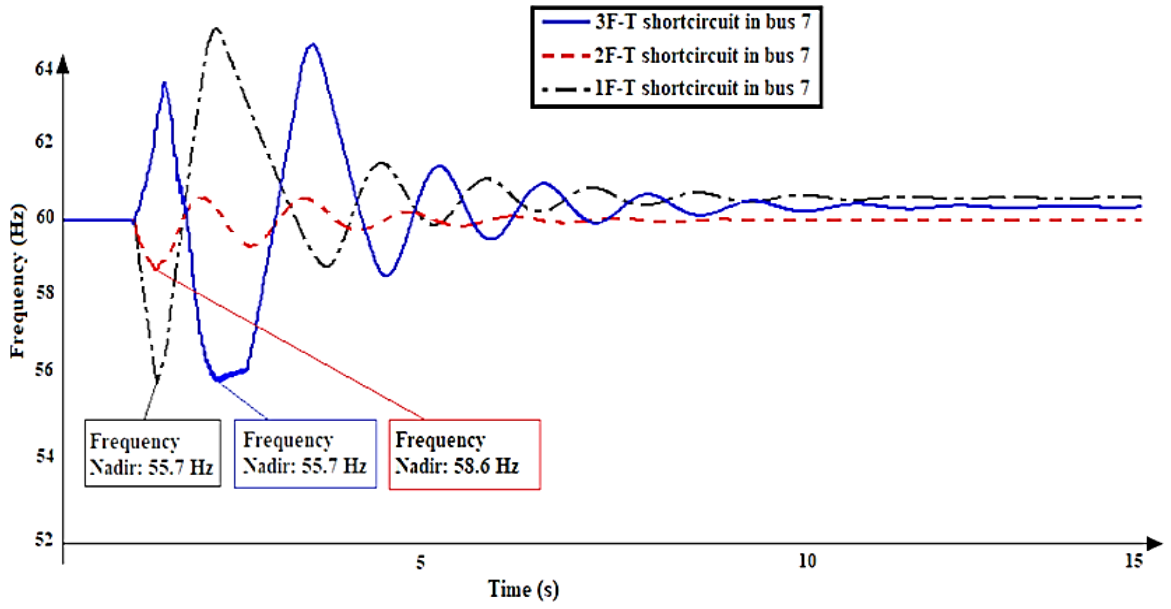

Figure 8. Frequency behavior for different types of short circuits

\subsection{Arc resistance influence}

The aspects tested above the impedance influence by generators when the fault occurs, and the terminal voltage imposed by the network on the generation nodes. The arc resistance is an additional resistance that appears during the fault and influences the value of the voltage module and angle. Figure 9 shows the behavior of the frequency when a single-phase short circuit with arc resistance occurs and when it is clean.

Figure 9 shows the difference in the frequency behavior when for the same type of short circuit and in the same node this occurs through arc resistance and when it is cleared a short circuit. The minimum frequency value in the case study occurs with an arc falls $1.21 \mathrm{~Hz}$ more than in the case where the fault is cleared. In both cases, the frequency drops, however, in the case where it occurs through an arc, the lowfrequency protections act, removing 5.8 MW from service. Therefore, it can be considered that there is a frequency instability problem in the case of the arcing fault, and yet the non-arcing fault itself does not cause an instability problem.

\subsection{Effect of the renewable energy penetration}

The frequency behavior in electrical systems is directly related toto the kinetic energy stored value in synchronous units that is certainly defined as real inertia. The photovoltaic penetration in the SEPs replaces synchronous generation. Also, for the same demand value, there is less inertia as the solar photovoltaic power increases online. Figure 10 shows the frequency behavior for two different generation compositions when a biphasic short-circuit to ground occurs in the power line that interconnects nodes 9 and 10 , with a cleaning time of $350 \mathrm{~ms}$. For a demand of $12.5 \mathrm{MW}$, two cases were analyzed, the first without photovoltaic solar generation and the second substituting a generation unit for $2.8 \mathrm{MW}$ supported by solar generation on the grid which represents a $22.5 \%$ penetration.

Figure 10 describes a marked difference in the frequency drops in both cases, the inclusion of power units that do not present inertia causes a $2.5 \mathrm{~Hz}$ additional frequency drop, the low frequency relay is activated avoiding an instability problem. Also, it is noticed in this simulation that with a higher renewable energy penetration exists a great speed frequency variation because the inertial response is reduced. This value of frequency drop speed can activate the protection operation responding to $\mathrm{df} / \mathrm{dt}$. 


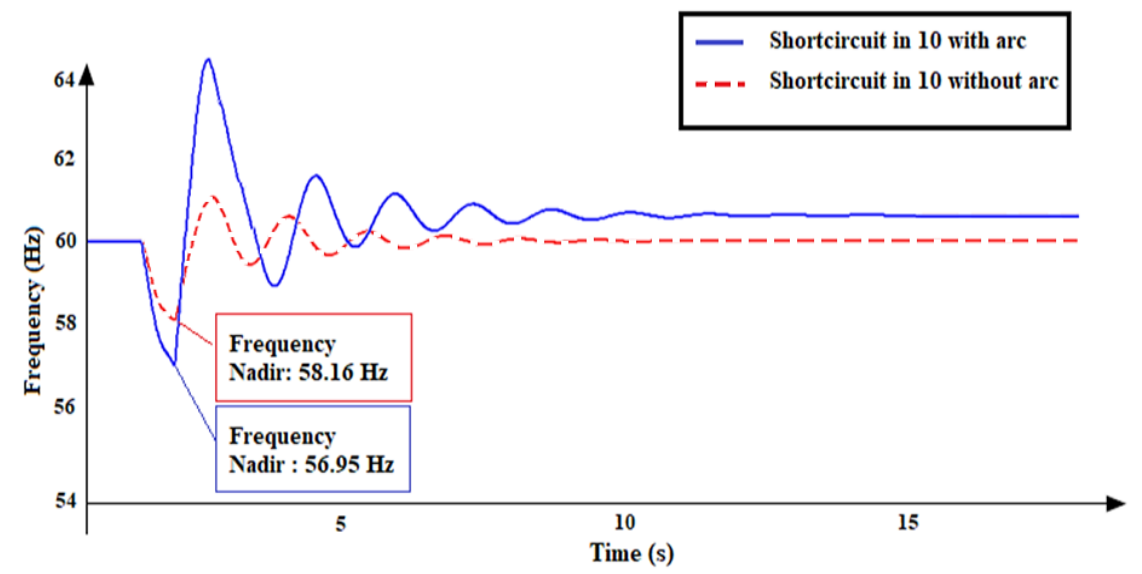

Figure 9. Behavior of the frequency under faults with the presence of the arc

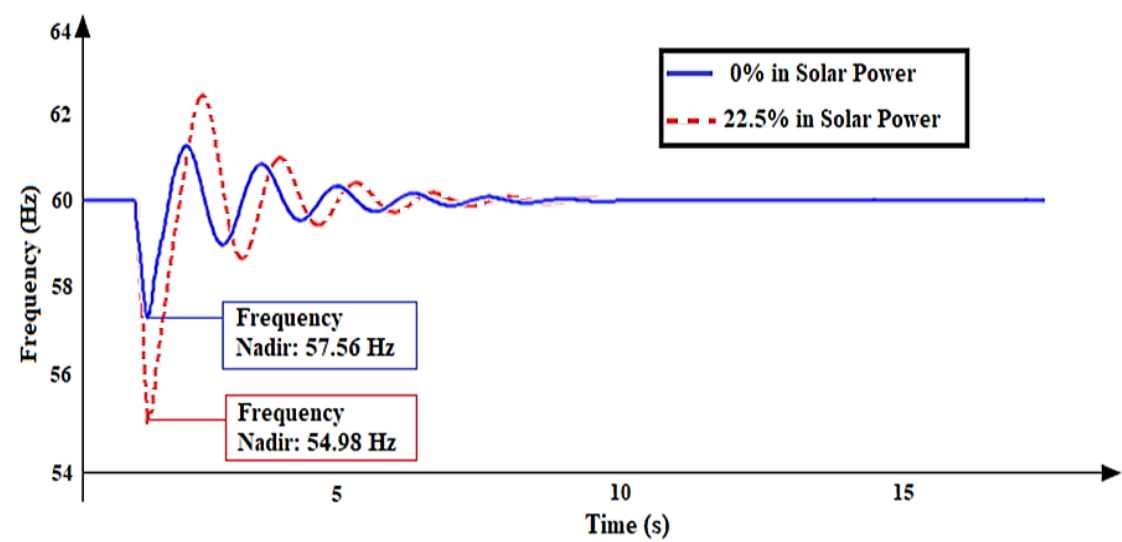

Figure 10. Frequency behavior in the event of a two-phase short circuit to ground in $75 \%$ of the line that interconnects nodes 9 and 10 for different penetration level of photovoltaic solar energy

\section{CONCLUSION}

The studies on frequency instability consider analysis of cases where large load generation imbalances occur, either due to a loss of generation or the entry of a load block. The occurrence of short circuits usually causes an acceleration of the synchronous units and therefore an increase in the frequency, this occurs in systems with large transmission networks, however in systems where networks with an R/X values greater than 1 predominates. In these cases, a short circuit can cause a sudden frequency drop

There are several factors that condition the response of generators to faults, the type of fault, the place where the fault occurs and whether it is with the presence of an arc or not, they affect the module and voltage angle and these in the electrical power delivered. The renewable energy sources penetration in the composition of the generation further accentuates this phenomenon of the frequency drop as it decreases the kinetic energy stored in the system, given the proportion of synchronous units in the total generation and therefore before it. Faults are more pronounced and frequency drops at higher speeds. The results showed that in weak networks that present units that do not contribute inertia to the network, short-circuit analyzes should be included to consider actions in order to prevent the occurrence of frequency instability.

\section{REFERENCES}

[1] D. I. Stroe, V. Knap, M. Swierczynski, A. I. Stroe, and R. Teodorescu, "Operation of a grid-connected lithium-ion battery energy storage system for primary frequency regulation: A battery lifetime perspective," IEEE Transactions on Industry Applications, vol. 53, no. 1, pp. 430-438, Jan. 2017, doi: 10.1109/TIA.2016.2616319.

[2] V. Knap, S. K. Chaudhary, D. I. Stroe, M. Swierczynski, B. I. Craciun, and R. Teodorescu, "Sizing of an energy storage system for grid inertial response and primary frequency reserve," IEEE Transactions on Power Systems, vol. 31, no. 5, pp. 3447-3456, Sep. 2016, doi: 10.1109/TPWRS.2015.2503565. 
[3] A. Benali, M. Khiat, and M. Denai, "Voltage profile and power quality improvement in photovoltaic farms integrated medium voltage grid using dynamic voltage restorer," International Journal of Power Electronics and Drive Systems, vol. 11, no. 3, pp. 1481-1490, Sep. 2020, doi: 10.11591/ijpeds.v11.i3.pp1481-1490.

[4] K. H. Chalok, M. F. N. Tajuddin, T. Sudhakar Babu, S. Md Ayob, and T. Sutikno, "Optimal extraction of photovoltaic energy using fuzzy logic control for maximum power point tracking technique," International Journal of Power Electronics and Drive Systems (IJPEDS), vol. 11, no. 3, Sep. 2020, Art. no. 1628, doi: 10.11591/ijpeds.v11.i3.pp1628-1639.

[5] L. Bougouffa and A. Chaghi, "Effect of renewable energy sources integration on the optimal coordination of directional overcurrent relays in distribution system," International Journal of Applied Power Engineering (IJAPE), vol. 9, no. 3, Dec. 2020, Art. no. 250, doi: 10.11591/ijape.v9.i3.pp250-255.

[6] M. Dris and B. Djilani, "Hybrid system power generation'wind-photovoltaic' connected to the electrical network $220 \mathrm{kV}$," International Journal of Applied Power Engineering (IJAPE), vol. 7, no. 1, Apr. 2018, Art. no. 10, doi: 10.11591/ijape.v7.i1.pp10-17.

[7] H. Pandzic, Y. Wang, T. Qiu, Y. Dvorkin, and D. S. Kirschen, "Near-optimal method for siting and sizing of distributed storage in a transmission network," IEEE Transactions on Power Systems, vol. 30, no. 5, pp. 2288-2300, Sep. 2015, doi: 10.1109/TPWRS.2014.2364257.

[8] V. Knap, R. Sinha, M. Swierczynski, D. I. Stroe, and S. Chaudhary, "Grid inertial response with Lithium-ion battery energy storage systems," in IEEE International Symposium on Industrial Electronics, Jun. 2014, pp. 1817-1822, doi: 10.1109/ISIE.2014.6864891.

[9] V. Sousa, H. Hernández, E. C. Quispe, J. R. Gómez, and P. R. Viego, “Analysis of harmonic distortion generated by PWM motor drives," 2017 IEEE Workshop on Power Electronics and Power Quality Applications (PEPQA), May 2017, pp. 1-6, doi: 10.1109/PEPQA.2017.7981644.

[10] S. A. Saleh, R. J. Meng, Z. G. Sanchez, O. A. Betancourt, and E. Ozkop, "The Selection of locations and sizes of battery storage systems using the principle component analysis and center-of-inertia," 2019 IEEE Industry Applications Society Annual Meeting, 2019, pp. 1-10, doi: 10.1109/IAS.2019.8911980.

[11] S. A. Saleh, E. Ozkop, R. J. Meng, Z. G. Sanchez, and O. A. A. Betancourt, "Selecting locations and sizes of battery storage systems based on the frequency of the center of inertia and principle component analysis," IEEE Transactions on Industry Applications, vol. 56, no. 2, pp. 1040-1051, Mar. 2020, doi: 10.1109/TIA.2019.2960003.

[12] N. A. Shalash and Y. N. Lafta, "PSS/E based placement wind/PV hybrid system to improve stability of Iraqi grid," International Journal of Electrical and Computer Engineering, vol. 10, no. 1, pp. 91-104, Feb. 2020, doi: 10.11591/ijece.v10i1.pp91-104.

[13] Y. M. Zhu, Y. Gong, and Z. G. Yang, "Failure analysis on over-temperature combustion of transformers in 4 MW offshore wind turbines," Engineering Failure Analysis, vol. 96, pp. 211-222, Feb. 2019, doi: 10.1016/j.engfailanal.2018.10.005.

[14] W. Strielkowski, D. Streimikiene, A. Fomina, and E. Semenova, "Internet of energy (IoE) and high-renewables electricity system market design," Energies, vol. 12, no. 24, Dec. 2019, Art. no. 4790, doi: 10.3390/en12244790.

[15] L. A. Trujillo Guajardo, A. Conde Enríquez, and Z. Leonowicz, "Error compensation in distance relays caused by wind power plants in the power grid," Electric Power Systems Research, vol. 106, pp. 109-119, Jan. 2014, doi: 10.1016/j.epsr.2013.08.009.

[16] V. N. Coelho, M. Weiss Cohen, I. M. Coelho, N. Liu, and F. G. Guimarães, "Multi-agent systems applied for energy systems integration: State-of-the-art applications and trends in microgrids," Applied Energy, vol. 187, pp. 820-832, Feb. 2017, doi: 10.1016/j.apenergy.2016.10.056.

[17] R. Ramakumar and P. Chiradeja, "Distributed generation and renewable energy systems," in Proceedings of the Intersociety Energy Conversion Engineering Conference, 2002, pp. 716-724, doi: 10.1109/iecec.2002.1392136.

[18] Q. Zhao, Y. Shen, and M. Li, "Control and Bidding Strategy for virtual power plants with renewable generation and inelastic demand in electricity markets," IEEE Transactions on Sustainable Energy, vol. 7, no. 2, pp. 562-575, Apr. 2016, doi: 10.1109/TSTE.2015.2504561.

[19] P. Mercier, R. Cherkaoui, and A. Oudalov, "Optimizing a battery energy storage system for frequency control application in an isolated power system," IEEE Transactions on Power Systems, vol. 24, no. 3, pp. 1469-1477, Aug. 2009, doi: 10.1109/TPWRS.2009.2022997.

[20] G. Delille, B. François, and G. Malarange, "Dynamic frequency control support by energy storage to reduce the impact of wind and solar generation on isolated power system's inertia," IEEE Transactions on Sustainable Energy, vol. 3, no. 4, pp. 931-939, Oct. 2012, doi: 10.1109/TSTE.2012.2205025.

[21] X. Chen, W. Du, and H. F. Wang, "Power system angular stability as affected by the reduced inertia due to wind displacing synchronous generators," in 2017 2nd International Conference on Power and Renewable Energy, ICPRE 2017, Sep. 2018, pp. 402-406, doi: 10.1109/ICPRE.2017.8390567.

[22] I. Egido et al., "Energy storage systems for frequency stability enhancement in small-isolated power systems," Renewable Energy and Power Quality Journal, vol. 1, no. 13, pp. 820-825, Apr. 2015, doi: 10.24084/repqj13.002.

[23] J. Baba, "Stabilizing small island power system with renewables by use of power conditioning systems - Japanese island system case-," in 2014 International Power Electronics Conference, IPEC-Hiroshima - ECCE Asia 2014, May 2014, pp. 1849-1854, doi: 10.1109/IPEC.2014.6869836.

[24] H. T. Nguyen, G. Yang, A. H. Nielsen, and P. H. Jensen, "Frequency stability enhancement for low inertia systems using synthetic inertia of wind power," in IEEE Power and Energy Society General Meeting, Jul. 2018, vol. 2018-January, pp. 1-5, doi: 10.1109/PESGM.2017.8274566.

[25] Z. G. Sanchez, J. A. G. C. Cruz, G. C. Sanchez, H. H. Herrera, and J. I. S. Ortega, "Voltage collapse point evaluation considering the load dependence in a power system stability problem," International Journal of Electrical and Computer Engineering, vol. 10, no. 1, pp. 61-71, Feb. 2020, doi: 10.11591/ijece.v10i1.pp61-71.

[26] R. M. Larik, M. W. Mustafa, and M. K. Panjwani, "A statistical jacobian application for power system optimization of voltage stability," Indonesian Journal of Electrical Engineering and Computer Science, vol. 13, no. 1, pp. 331-338, Jan. 2019, doi: 10.11591/ijeecs.v13.i1.pp331-338.

[27] J. P. Sridhar and R. Prakash, "Multi-objective whale optimization based minimization of loss, maximization of voltage stability considering cost of DG for optimal sizing and placement of DG," International Journal of Electrical and Computer Engineering (IJECE), vol. 9, no. 2, p. 835, Apr. 2019, doi: 10.11591/ijece.v9i2.pp835-839.

[28] P. Kundur et al., "Definition and classification of power system stability," IEEE Transactions on Power Systems, vol. 19, no. 3, pp. 1387-1401, Aug. 2004, doi: 10.1109/TPWRS.2004.825981

[29] IRENA, "Transforming small-island power systems: Technical planning studies for the integration of variable renewables," Abu Dhabi: International Renewable Energy Agency (IRENA), 2018.

[30] L. Sigrist, E. Lobato, F. M. Echavarren, I. Egido, and L. Rouco, "Island power systems," CRC Press, 2016. 


\section{BIOGRAPHIES OF AUTHORS}

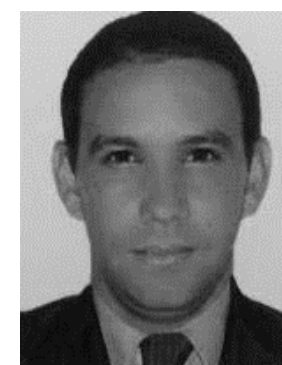

Marino Godoy Arcia (D) SC SC Electrical Engineer Student of the Master's Degree in Energy Efficiency at the University of Cienfuegos, Cuba. He can be contacted at email: mgodoy@ucf.edu.cu.

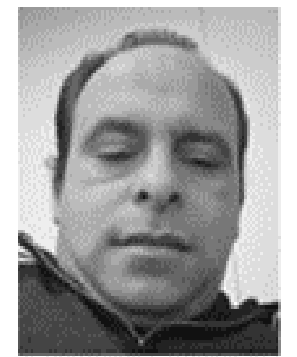

Zaid Garcia Sanchez (D) SC SC Electrical Engineer from the Universidad Central de las Villas, Cuba in 2002. Master of Science in Electric Power Systems in 2004 and (Ph.D.) degree from the Universidad Central de las Villas, Cuba in 2011. Full Professor, Center for Energy and Environment Studies (CEEMA), University of Cienfuegos. His area of interest includes power systems modelling and stability, Renewable Energy Sources and Smart Grid. He can be contacted at email: zgarcia@ucf.edu.cu.

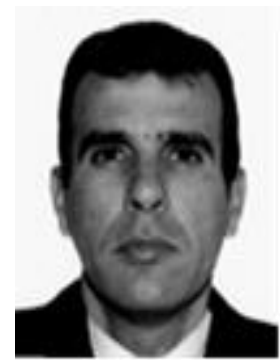

Hernan Hernández Herrera (iD 81 SC P Mechanical Engineering from the Universidad de Cienfuegos, Cuba in 2000. M. Sc. in applied mechanics from the Universidad de Cienfuegos, Cuba 2005. Received the (Ph.D.) degree from the Universidad de Cienfuegos, Cuba, in 2006. Currently is professor of plant in the faculty of mechanical engineering in the University Simón Bolívar, Colombia. His area of interest includes applied mechanics, energy efficiency and renewable energy sources. He can be contacted at email: hernanhh813@gmail.com.

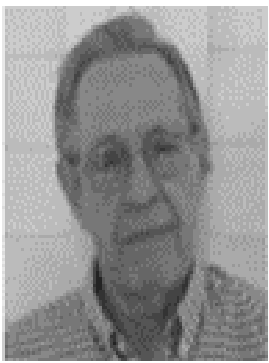

José Antonio González-Cueto Cruz (D) $8 \mathrm{~d}$ SC Plectrical Engineer, Master of Science, Doctor of Technical Sciences, Senior Associate Professor, Center for Electro energetic Studies (CEE), Central University "Marta Abreus" de las Villas. He can be contacted at email: jcueto@uclv.edu.cu.

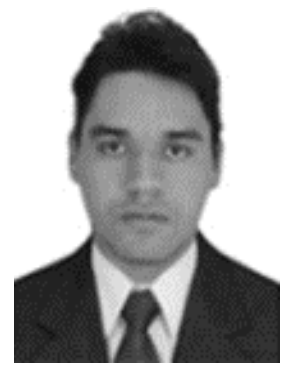

Jorge Iván Silva Ortega (D) $\mathrm{SC}$ S $\mathrm{P}$ is Electrical and Electronic Engineer, Master in Electrical Engineering (2013) from the Universidad del Norte, Colombia. Ph.D. student in Engineering at the Universidad Pontificia Bolivariana in Medellín, Colombia. Professor and researcher of the Universidad de la Costa, Colombia. Joined to Research Group on Energy Optimization (GIOPEN). His research interests include: electrical power systems, Electrical Engineering education; planning, operation, and control of power systems; and intelligent electrical networks. He can be contacted at email: jsilva6@cuc.edu.co.

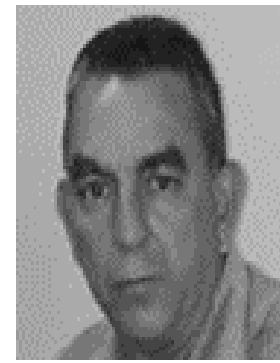

Gustavo Crespo Sánchez (D) 8d SC P Electrical Engineer, Master of Science, Assistant Professor, Center for Energy Studies and Environment (CEEMA), University of Cienfuegos. He can be contacted at email: gcsánchez@ucf.edu.cu. 